\title{
Analysis, Modelling and Design Considerations for the Excitation Systems of Synchronous Generators
}

\author{
Stefano Nuzzo, Student Member, IEEE, Michael Galea, Member, IEEE, \\ Chris Gerada, Senior Member, IEEE and Neil Brown
}

\begin{abstract}
The traditional generating set is usually comprised of a classical, wound-field, salient-pole or cylindrical rotor synchronous generator, excited by a separate smaller machine, via a rotating, uncontrolled diode rectifier. The effects of the commutation processes of the diode bridge are often overlooked and neglected. However due to the uncontrolled nature of this process, the rectified voltage available at the main generator's rotor terminals can be significantly lower than the expected value. This is especially true for low-to-medium power rated systems.

In this paper, a detailed investigation of these aspects is done and an accurate voltage drop prediction model is then proposed. The model is validated with finite element analysis and with experimental results for a particular low-medium rated generating system in the $400 k V A$ power range. The validated tool is then integrated into an innovative design tool, which first performs an analytical pre-sizing procedure and then utilizes a genetic algorithm approach to identify an optimal excitation system design, aimed at minimizing the voltage drop ensuing from the diode commutations, with minimum impact on the overall efficiency.
\end{abstract}

Index Terms-Excitation Systems, Synchronous Generators, Diode Commutations, Rotating Rectifier.

\section{INTRODUCTION}

$\mathrm{T}$ HE excitation system of classical, wound-field, Synchronous Generators (SGs) is a subpart of a relatively complex feedback control system, whose primary function is maintaining the output voltage constant at the main machine's stator terminals. This function is accomplished by regulating the output voltage of the exciter through control of its field current. Traditionally, the latter is transferred from the exciter to the SG by using a commutator, slip rings and brushes. In recent times, the utilization of this solution has seen a significant decrease, mainly because brushes can produce

Manuscript received February 06, 2017; revised March 30, 2017; June 27, 2017 and July 28, 2017; accepted September 06, 2017.

S. Nuzzo, M. Galea and C. Gerada are with the Power Electronics, Machines and Control Group, University of Nottingham, Nottingham, UK (e-mail: stefano.nuzzo@nottingham.ac.uk).

C. Gerada and M. Galea are with the Power Electronics, Machines and Control Group, University of Nottingham Ningbo, Ningbo, China (e-mail: chris.gerada@nottingham.ac.uk).

N. Brown is with Cummins Power Generation, Peterborough, UK; (e-mail: neil.brown@cummins.com). significant resistive voltage drops and need periodical maintenance and replacement [1]. A more robust and modern solution is that of providing the excitation current by employing a brushless excitation system, consisting of a small "inside-out" electrical machine whose three phase output voltages are rectified by a rotating bridge and fed to the main generator's field winding. The field current is then regulated by an Automatic Voltage Regulator (AVR), which is powered either by a permanent magnet generator (pilot exciter) in separately-excited systems or by the SG residual voltage in self-excited systems. An example of a brushless, self-excited, control system is shown in Fig. 1. Guides for standard definitions and specifications of all the parts of a control excitation system are provided in [2] and [3].

In such systems, an often overlooked aspect is that of the design and operation of the rotating rectifier. The most common configuration (for economic reasons) used in the brushless excitation systems of SGs consists of a six-pulse diode bridge. The diodes' commutation modes typically occurring in these uncontrolled rectifiers have been extensively studied in literature [4-6]. However, for some applications, such as power generating sets (GenSets), these processes are often neglected. In particular, for GenSets where the equivalent circuit's parameters of the exciter are comparable with those of the main machine, the voltage drop caused by these commutations can be significantly large. In Section II, these aspects will be preliminary recalled, showing that the supply inductance of the system plays the most important role in producing this drop and that, therefore, it has to be taken into account in the design process of the exciter, as it can have significant effects on the operation and efficiency of the entire GenSet.

In this paper a detailed analysis of these aspects is presented and an accurate model for the prediction of the performance is proposed. In the second part, this work deals with the development of a Genetic-Algorithm (GA) optimization design tool, aimed at reducing the voltage drop due to the diodes' commutations, with minimum disruption on the machine design, while keeping the efficiency of the machine above acceptable limits. Special focus is given to the principal operation of the Genset, i.e. the rated, full-load condition. As vehicle for investigating this study, a $5.35 \mathrm{kVA}$ excitation system is considered and its major features are described in the following section. 


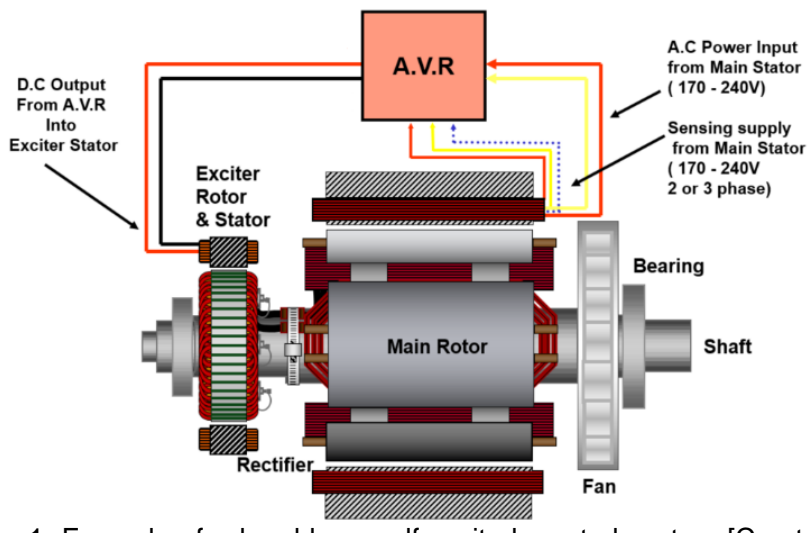

Fig. 1. Example of a brushless, self-excited, control system [Courtesy of Cummins Power Generation].

\section{A. The considered platform}

All the analytical, numerical and experimental results that will be reported in this paper refer to an industrial $400 \mathrm{kVA}$ GenSet. The main alternator is a three-phase machine featuring 4 rotor poles, 48 stator slots with skewing and 6 damping bars per pole, designed to provide a rated voltage of $400 \mathrm{~V}(50 \mathrm{~Hz})$ with a Y-connection of the armature phases. This is achieved with field voltages and currents of $20.5 \mathrm{~V}$ and $14.4 \mathrm{~A}$ at no-load and $101.5 \mathrm{~V}$ and $50 \mathrm{~A}$ at full-load. The perceived difference in the field winding resistance (i.e. between the no-load and full load operating points) is due to a winding temperature rise of $\approx 100^{\circ}$ from no-load to full-load operation.

The SG residual voltage of the machine is used to power the AVR. This voltage is then rectified and controlled in order to supply the exciter field winding in such a way that the voltage level at the generator terminals is maintained constant. The "inside-out" machine that acts as the exciter produces a threephase system of voltages at its rotor terminals, which in turn are connected to a 6-pulse bridge rectifier. The voltage rectified by this diode bridge feeds the field winding of the generator, which finally closes the loop by generating the desired output voltage.

The excitation system of the GenSet under analysis is designed to provide $\approx 5 \mathrm{~kW}$ (DC) to the field winding of the main SG, when the latter operates at full-load condition. The considered rated apparent power of the machine (i.e. $5.35 \mathrm{kVA}$ ) is obtained from the rectified voltage and current values needed by the alternator at full-load operation (i.e. $101.5 \mathrm{~V}$ and $50 A$ respectively), opportunely transformed from $\mathrm{DC}$ to $\mathrm{AC}$ quantities. However, it is worth to clarify that the rated power of $5.35 \mathrm{kVA}$ is used as a landmark value in the paper. In fact, the exciter design is carried out by taking into account that this machine has to also 'cater' for the ceiling performance of the main SG. In particular, the considered ceiling factor for the voltage and the current is equal to 2 , resulting in a "real" apparent power which is 4 times larger than the base value used in this paper.

The exciter features a 14 poles field winding placed on the stator and a three phase armature winding on the rotor. The machine is characterized by a low aspect ratio $l / D$ (axial length/outer diameter), making its design quite compact. In order to minimize the manufacturing costs and simplify the inherent processes, the same magnetic material is employed for both the main generator and the exciter. In Table I, a summary regarding the major features of the considered exciter is shown as well as the major ratings of the rotating silicon diodes used in the uncontrolled rectifier which is part of the considered GenSet.

TABLE I

MACHINE AND DIODE PARAMETERS

\begin{tabular}{|c|c|c|c|}
\hline \multicolumn{2}{|c|}{ Exciter } & \multicolumn{2}{c|}{ Diodes } \\
\hline Parameter & Value & Parameter & Value \\
\hline Rated Power & $5.35 \mathrm{kVA}$ & $\mathrm{I}_{\mathrm{F}(\mathrm{AV}) \mathrm{r}}$ & $36 \mathrm{~A}$ \\
\hline Rated Voltage & $75 \mathrm{~V}$ & $\mathrm{~V}_{\mathrm{RRM}}$ & $1400 \mathrm{~V}$ \\
\hline Rated Frequency & $175 \mathrm{~Hz}$ & $\mathrm{I}_{\mathrm{FSM}}$ & $480 \mathrm{~A}$ \\
\hline Stator Pole Number & 14 & $\mathrm{I}^{2} \mathrm{t}$ & $1050 \mathrm{~A}^{2} \mathrm{~s}$ \\
\hline Rotor Slot Number & 42 & Thermal resistance & $4 K / \mathrm{W}$ \\
\hline Magnetic Material & M700-65A & Alternative package & $\mathrm{DO}-203 \mathrm{AB}$ \\
\hline
\end{tabular}

\section{ANALYSIS OF THE COMMUTATION PROCESSES IN DIODE RECTIFIERS}

The equivalent circuit of a brushless exciter for power GenSets is shown in Fig. 2. If a three-phase system of alternating voltages is feeding the diode rectifier, then at any instant in time two diodes of different levels and legs conduct (e.g. D1 and D2). In simplistic terms, these are the diode with the most positive potential on its anode and that with the most negative potential on its cathode.

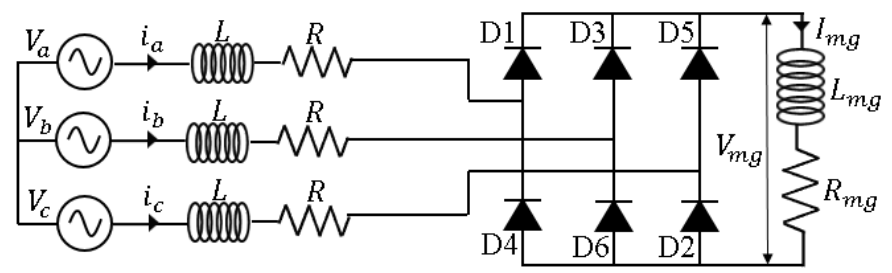

Fig. 2. Basic circuit of a three-phase star-connected exciter feeding into a three-phase bridge rectifier.

\section{A. Considerations for large GenSets}

As mentioned above, in large GenSets, where the equivalent circuit's parameters of the main SGs are much bigger than those of their excitation systems, the effects of such electromagnetic quantities of the exciter are often neglected from the equivalent circuit analysis of the GenSet and also the bridge rectifier operation is usually considered ideal. Thus, if a DC current $I_{m g}$ is absorbed by a particular load, the currents $i_{a}, i_{b}$ and $i_{c}$ on the AC side are ideally rectangular and their amplitudes are theoretically equal to $I_{m g}$. The rectified voltage consists of $n$ sinusoidal peaks per cycle, where $n$ is the number of diodes present in the $\mathrm{AC} / \mathrm{DC}$ rectifier.

\section{B. Considerations for small-medium GenSets}

Considering that a preliminary analysis of the equivalent circuit's parameters has to be carried out also in applications where relatively large SGs are used, it is however reasonably true that, for low-to-medium rated GenSets, the characteristic 
parameters of the exciter can feature values comparable to those of the main generator. Here, the delay that the supply inductance $L$ creates in the diodes' commutations may become very important and can significantly affect the performance of the uncontrolled diode bridge. One of the most important aspects of this is the potential overlap in the conduction periods of the diodes. If the commutation takes less than " $1 / n$ th" of one period, the process is called simple commutation. It the transfer process takes more than " $1 / n-t h$ " of the period, then the operation mode is called multiple commutation. Besides these two modes of operation, there is also the possibility that the commutation time is exactly " $l / n$ - $t h$ " of one period. These three operating modes have been extensively dealt with in literature [7-9], however without detailing the operation of the simple commutation during normal operation of the main SG. This is investigated in the next section and a model including the effect of the supply resistance is also presented.

\section{The simple commutation}

Traditionally, this operating mode is modelled in its classical form, which includes only the effect of the supply inductance. An accurate and modern way of modelling is presented here, where the effects that the supply resistance $R$ (i.e. the phase resistance of the exciter for the application at hand) has on the diode rectifier behavior are also taken into account. Considering a six-pulse bridge, such as the one shown in Fig. 2 and assuming that

1) all the diodes are ideal,

2) the current absorbed by the load is constant (DC),

3) the current absorbed by the diodes have a sloped shape during the commutation (as shown in Fig. 3),

then the time dependence of the currents $i_{D n}(t)$ in the diodes can be described by (1).

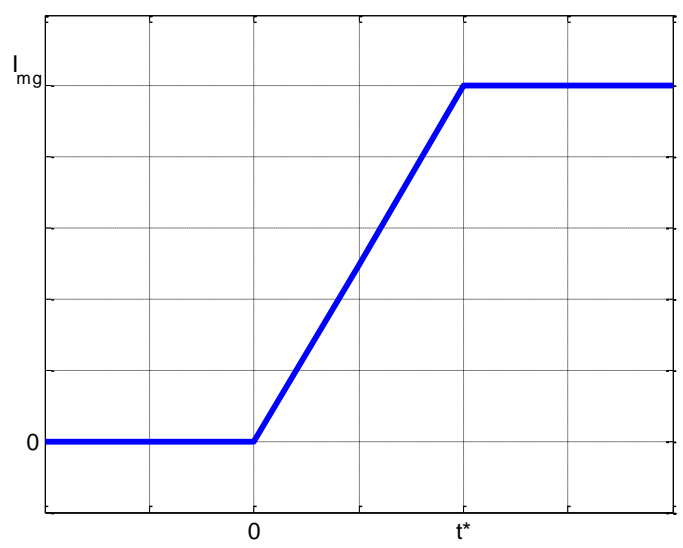

Fig. 3. Hypothesis on the diodes' current waveform.

$$
i_{D n}(t)=\frac{I_{m g} \cdot t}{t^{*}}
$$

During commutation, two phases are short-circuited, say phases $v_{a}$ and $v_{b}$. In this subinterval, the following expressions can be therefore written for the circuit of Fig. 2.

$$
i_{a}(t)+i_{b}(t)=I_{m g}
$$

$$
\begin{gathered}
v_{a}(t)-R \cdot i_{a}(t)-L \cdot \frac{d i_{a}(t)}{d t}=v_{b}(t)-R \cdot i_{b}(t)-L \cdot \frac{d i_{b}(t)}{d t} \\
\frac{v_{a b}(t)+R \cdot I_{m g}}{2}=R \cdot i_{a}(t)+L \frac{d i_{a}(t)}{d t}
\end{gathered}
$$

By integrating all the terms of (3) during the commutation subinterval, i.e. between 0 and $t^{*}$, then an expression for the commutation angle $\mu$ can be obtained as given in (5), where it can be seen that, under the assumption (1), the inclusion of $R$ in the model has no effect on the commutation angle. In (5), $V_{L L}$ is the RMS value of the line-to-line voltage and $\omega$ the supply angular frequency. On the other hand, in order to obtain the rectified load voltage $V_{m g}$, (6) can be written for the circuit of Fig. 2 and, through the use of (4), the final expression (7) can be derived, highlighting now that the effect of the phase resistance cannot be neglected

$$
\begin{gathered}
\mu=\arccos \left(1-\frac{2 \cdot \omega \cdot L \cdot I_{m g}}{V_{L L} \cdot \sqrt{2}}\right) \\
v_{a}(t)-R \cdot i_{a}(t)-L \frac{d i_{a}(t)}{d t}-v_{c}(t)-V_{m g}=0 \\
V_{m g}=\frac{1}{2}\left(v_{a c}(t)+v_{b c}(t)-R \cdot I_{m g}\right)
\end{gathered}
$$

In classical theory dealing with the simple commutation mode, the phase resistances are not considered in the model. In fact, by neglecting $R$ in equations (3)-(7), the well-known expressions relevant to the rectifier model can be easily derived.

\section{Further considerations}

In the previous sections, it has been shown how the supply inductance can negatively affect the average value of the voltage rectified by an uncontrolled diode rectifier. This effect can be observed through the angle $\mu$ of Fig. 4, where the wellknown waveform that can be registered after rectifying a three-phase system of sinusoidal voltages through a six-pulse diode bridge is shown.

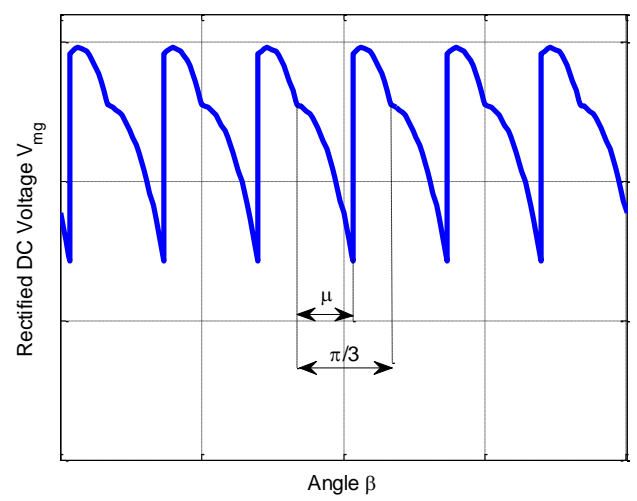

Fig. 4: Average DC voltage in simple commutation mode. 
The simple commutation model has been extended by including the effects of the resistance on the diode rectifier behaviour. The expressions for the rectified voltage and the commutation angle have been provided in (5)-(7), where it can be observed that, if $I_{m g}$ is maintained constant, the commutation angle can be reduced by

1) Decreasing the supply angular frequency $\omega$,

2) Decreasing the supply inductance $L$,

3) Increasing the supply AC voltage $V_{L L}$.

It is also important to show an expression for the voltage drop $\Delta V_{m g}$ ensuing from the commutation processes, when for example the simple commutation mode mentioned above occurs. This can be obtained by integrating the voltage drop due to the inductance and to the resistance over the commutation angle. Hence, for a six-pulse bridge rectifier, this can be described by (8), while if $R$ was to be neglected (as done in classical theory), then $\Delta V_{m g}$ in its simplified form is given in (9).

$$
\begin{gathered}
\Delta V_{m g}=\frac{3}{\pi}\left(\omega \cdot L \cdot I_{m g}+\frac{R \cdot I_{m g} \cdot \mu}{2 \cdot \omega}\right) \\
\Delta V_{m g}=\frac{3 \cdot \omega \cdot L \cdot I_{m g}}{\pi}
\end{gathered}
$$

All the above confirms the importance of the supply inductance $L$, i.e. the phase inductance of the exciter, as a key parameter for determining the voltage drop. The models developed and used to estimate the machine inductance and the voltage drop are described in the following sections.

\section{The INDUCtANCE CALCULATION}

Considering the importance of accurately estimating the phase inductance of the exciter, then an analytical expression of the inductance matrix $L(\gamma)$ is developed based on the representation of a generic electrical machine, as given in (10).

$$
L(\gamma)=l \cdot \int_{0}^{2 \pi} \mu_{E}(\beta, \gamma) \cdot \overline{N_{E}}(\beta, \gamma) \cdot{\overline{N_{E}}}^{T}(\beta, \gamma) \cdot d \beta
$$

The analytical derivation of (10) is entirely shown in [10] and is based on an equivalent-circuit-based approach. In (10), $\beta$ is the rotor angular reference frame and $\gamma$ is the mechanical state variable, i.e. the angular position of rotor vs. stator. The vector $\overline{N_{E}}(\beta, \gamma)$ contains all the equivalent Winding Functions (WFs) $N_{E i}[9,10]$ of the machine phases, whereas $\mu_{E}(\beta, \gamma)$ is the equivalent magnetic permeability function, whose expression is given in [10] and [11]. It is important to note that the equivalent functions mentioned above contain all the information necessary for the phase self-inductance calculation, namely the anisotropies of the machine, the position of the active sides of the coil, the number of conductors per coil, etc. The main assumption behind (10) is the absence of saturation in the ferromagnetic materials. This allows one to consider the inductance $L(\gamma)$ as only depending on $\gamma$ and not on the currents flowing in the machine windings.
This hypothesis is justified for the application at hand as the exciters of SGs are designed for operating in linear conditions when the main machine operates at full-load. Another important assumption of the model is the neglecting of secondary phenomena, such as hysteresis and eddy currents.

Considering the structural symmetric nature of most electrical machines, then it can be observed that the periodicity of the electrical quantities (i.e. $\left.N_{E i}(\beta, \gamma)\right)$ introduced in (10) is $2 \pi / p$ (where $p$ is the pole pair number), while the geometrical quantities involved in $\mu_{E}(\beta, \gamma)$ have a periodicity which is instead half of that of the equivalent WFs. Considering this and referring to the approach shown in [10], all these functions can be developed in a Fourier series with respect to $\beta$. In particular, when a sinusoidal approximation is considered, only the mean values and the fundamental components are involved. Hence, the main self-inductance of the phase A of the exciter can be calculated and this is shown in Fig. 5. Also, due to the potential impact that the leakage fluxes can have on the particular aspect being considered in this work, an accurate evaluation (based on [12]) of the inherent inductances is carried out, including 1) the airgap leakage inductance $L_{a g}, 2$ ) the slot leakage inductance $L_{\text {slot }}, 3$ ) the pole tip leakage inductance $L_{p t}$ and 4 ) the end-winding leakage inductance $L_{e w}$.

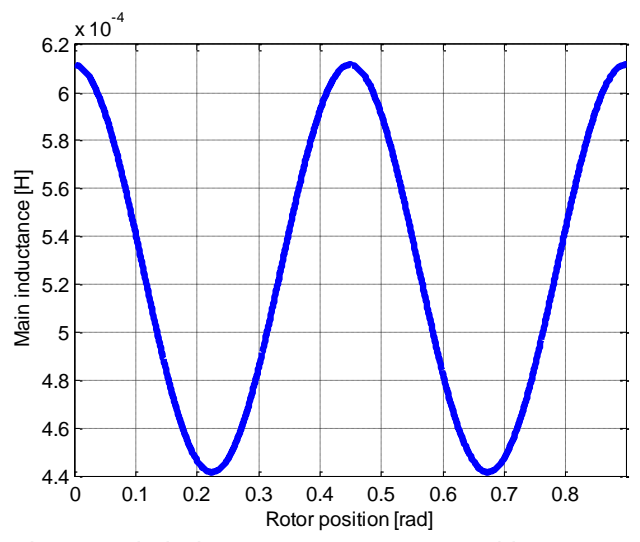

Fig. 5. A-phase main inductance as vs. rotor position.

The main inductance $L$ shown in Fig. 5 and the calculated leakage inductances are used in (5) to evaluate $\mu$ and then in (8) to calculate $\Delta V_{m g}$.

Considering the diode rectifier of the brushless excitation system analyzed in this paper, then the calculated value is $\Delta V_{m g}=32.3 \mathrm{~V}$, which is about $30 \%$ of the DC voltage needed by the rotor of the main SG when operating at full-load condition. Having determined $\Delta V_{m g}$, then this can be used to recalculate the exciter output AC voltage $V_{L L \_N E W}$ needed to compensate for it, as given in (11), where the classical rectifiers' theory is utilized to transform from DC to $\mathrm{AC}$ quantities [4]. The calculated inductance and the updated $V_{L L_{-} N E W}$ can then be used in (5) to re-evaluate $\mu$.

$$
V_{L L_{-} N E W}=\frac{\Delta V_{m g}+V_{L L}}{1.35}
$$

All the above confirms that the voltage drop to the commutations can be significantly large in low-to-medium rated SGs. In order to validate the proposed analysis for the 
inductance calculation and the ensuing $\Delta V_{m g}$, a 2-D FiniteElement (FE) model of the exciter is built, whose details are given in the following section. Furthermore, experimental measurements are shown for the same validation purposes.

\section{MOdEL VALIDATION THROUGH FE ANALYSIS AND EXPERIMENTAL TESTS OF THE EXCITER}

It is well known that an in-detail, FE analysis is more accurate than analytical approaches, especially when complex electromagnetic phenomena have to be accounted for. Also, the commutation processes have to be considered for the sake of this study.

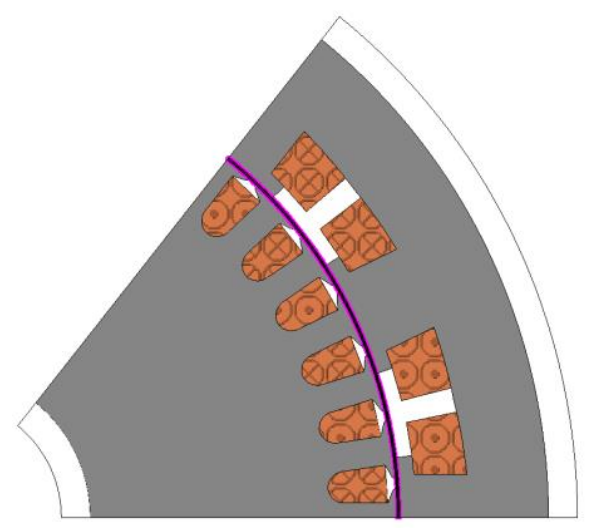

Fig. 6. 1 pole pair model of the $5.35 \mathrm{kVA}$ exciter.

\section{A. FE Model}

A 2-D FE model is then built in order to achieve accurate results while minimizing the required computational resources (as opposed to a 3-D model). As described in [13] and [14], a number of circuital lumped resistances are coupled to the model to account for the end connections. To take advantage of the geometrical symmetries characterizing the machine, only " $1 / 7-t h$ " of the whole exciter is analyzed. The developed model is shown in Fig. 6. Test simulations are performed by coupling stator and rotor circuits to the FE model.

Considering all the above, static simulations have been carried out to calculate the inductances of the machine, according to the method described in [15]. This consists in evaluating the $d$ - and $q$-axis inductances of the machine, allowing for the leakage inductances to be taken into account. Only the end-winding leakage inductance is not considered in the evaluation, as a 2-D FE model has been used for the analysis. The above-determined inductances are then used to evaluate $\Delta V_{m g}$. Furthermore, transient with motion simulations have been carried out in order to estimate $\mu$ and $V_{L L}$ needed for maintaining the DC voltage and current on the main rotor at the desired values.

The current in two diodes (implemented as ideal devices in the circuit coupled with the corresponding FE model described above) during the conduction overlap are shown in Fig. 7, which also highlights the value of the commutation angle.

From Fig. 7, it can also be observed how (1) is valid for the application at hand, as the current waveform is very similar to that of Fig. 3, allowing for a further validation of the relationships derived and described by (7) and (8) for the evaluation of $V_{m g}$ and $\Delta V_{m g}$. Finally, a summary of the comparison between analytical and FE results is shown in
Table II, where an excellent match can be observed.

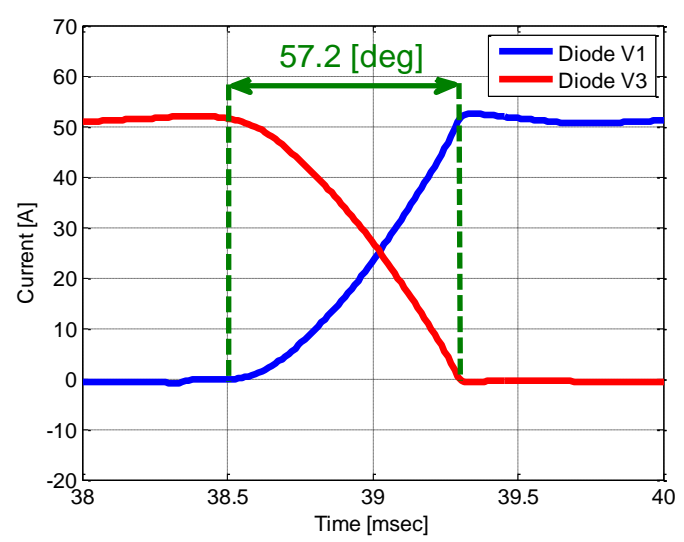

Fig. 7. Currents in 2 diodes during the commutation interval.

TABLE II

COMPARISON BETWEEN ANALYTICAL AND FE RESULTS

\begin{tabular}{|c|c|c|c|}
\hline Parameter & Analytical & FE & Error \\
\hline Phase Inductance & $0.61 \mathrm{mH}$ & $0.59 \mathrm{mH}$ & $3.28 \%$ \\
\hline Voltage Drop & $32.3 \mathrm{~V}$ & $31.1 \mathrm{~V}$ & $3.72 \%$ \\
\hline Commutation Angle & $58.9^{\circ}$ & $57.2^{\circ}$ & $2.89 \%$ \\
\hline Line-To-Line Voltage & $101 \mathrm{~V}$ & $107 \mathrm{~V}$ & $5.61 \%$ \\
\hline
\end{tabular}

From Fig. 7, it can also be observed how (1) is valid for the application at hand, as the current waveform is very similar to that of Fig. 3, allowing for a further validation of the relationships derived and described by (7) and (8) for the evaluation of $V_{m g}$ and $\Delta V_{m g}$. Finally, a summary of the comparison between analytical and FE results is shown in Table II, where an excellent match can be observed.

\section{B. Experimental Validation}

In order to further validate the models described above, experimental measurements on the studied platform were also performed. Fig. 8 shows the rotor of the exciter being tested, the diode rectifier and the rotor of the main SG.

To evaluate the no-load characteristic of the considered exciter, slip rings were used for the reading of the values of the line-to-line rotor voltages, while the main generator's field winding was disconnected, otherwise there would be currents flowing in the exciter armature. The exciter's field current was instead varied through a separate power supply. Fig. 9 shows the comparison of the experimental no-load curve with the FE open-circuit characteristic of the $5.35 \mathrm{kVA}$ exciter, with a very good similarity being achieved along a large range of the field current values. In the same figure, an analytical evaluation of the no-load characteristic is also shown, according to the sizing tool which will be described in the next section. It can be also noticed in Fig. 9 that the voltage values (y-axis) are reported in p.u. (where the value of 1 p.u. corresponds to $75 \mathrm{~V}$ ), while the field current values are expressed in the standard unit of measurement.

After the tests described above, then in order to determine the value of the exciter field current needed for providing the rated DC power to the main generator, a more complex test set-up was necessary. The main generator was mechanically connected to a dynamometer capable to run the machine at the 
requested speed and load. The machine was loaded through appropriate resistive and reactive load banks, while the exciter field winding was connected to the AVR, reproducing the real world operation of the whole Genset. In these conditions, the main generator field voltage $V_{m g}$ and current $I_{m g}$ were equal to the rated values, i.e. $101.5 \mathrm{~V}$ and $50.1 \mathrm{~A}$ respectively. These values are in line with the analytical and the FE results as these were also carried out with the aim of achieving the rated values at the generator's field winding terminals. During the test, the exciter field current was registered, resulting in a corresponding value of $V=108 \mathrm{~V}$ on the experimental no-load curve of Fig. 9. This value, which again shows a very good match between analytical and $\mathrm{FE}$ results, corresponds therefore to the internal voltage $\left(V_{a}-V_{b}\right.$ in Fig. 2) that the machine provides in order to compensate for the resistive and inductive voltage drops due to the exciter impedance and to the commutations. Also the corresponding, analytical and FE voltage values (shown in Table III) evaluated in the previous sections, take into account this voltage drops, making the comparison highly fair and reliable.

Further validation of the proposed models is also provided by the measurement of the phase inductance through an RLC meter, connected to the rotor terminals of the machine. The number of the measures taken during this test was 8 (at different rotor positions) and the inductance value was calculated by averaging processes, at the rated frequency of the exciter. The inductance calculated with such method was equal to $0.56 \mathrm{mH}$, showing again a very close match with the analytical- and FE-evaluated values. A summary of this comparison is given in Table III.

TABLE III

ANALYTICAL, FE AND EXPERIMENTAL RESULTS: SUMMARY OF THE COMPARISON

\begin{tabular}{|c|c|c|c|}
\hline Parameter & Analytical & FE & Experimental \\
\hline Exciter Field Current & $2.54 \mathrm{~A}$ & $2.42 \mathrm{~A}$ & $2.37 \mathrm{~A}$ \\
\hline Voltage & $101 \mathrm{~V}$ & $107 \mathrm{~V}$ & $108 \mathrm{~V}$ \\
\hline Phase Inductance & $0.61 \mathrm{mH}$ & $0.59 \mathrm{mH}$ & $0.56 \mathrm{mH}$ \\
\hline
\end{tabular}

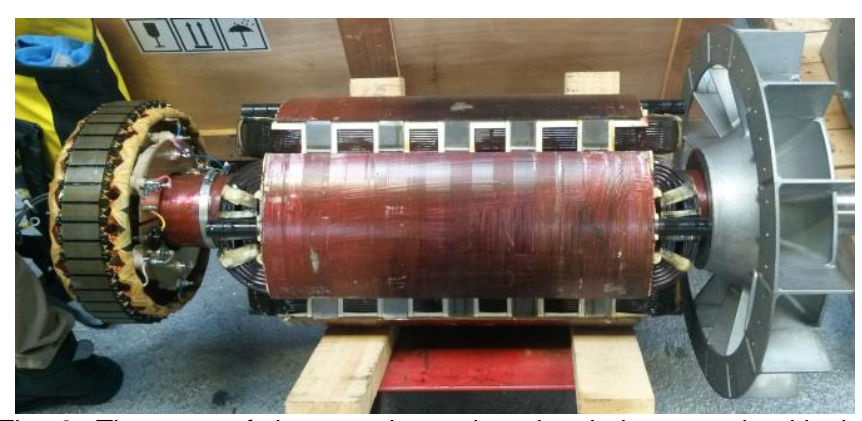

Fig. 8. The rotor of the experimental exciter being tested, with the rotating diode bridge feeding the rotor of the main synchronous generator.

\section{Conclusive Considerations}

All the above (proposed analytical models, FE results and experimental validation) indicate and show that the commutation processes cannot be neglected in the design of the exciter being analysed in this paper. In particular, it is shown how an excellent prediction of the inherent cause and effect of these processes (i.e. the supply inductance and the voltage drop) can be achieved without resorting to invasive techniques aimed at "directly" measuring the diodes' currents and voltages. The main causes and effects of the described phenomena have been demonstrated to match very well with the measurements (as shown in Table III) thus proving the validity of the proposed methodologies. Having thus predicted these parameter by using (10) and (8) respectively for $L$ and $\Delta V_{m g}$, it becomes possible through the use of (11) to estimate the real AC voltage value at which the exciter has to work to provide the necessary power to the main rotor. During the actual operation of the GenSet, $V_{L L}$ represents the only variable that the system can manipulate to compensate for $\Delta V_{m g}$. It is clear then that this is not an optimal performance solution, as the exciter will be overloaded even during the normal operation of the main alternator. However, the oversizing philosophy used for the machine design allows the requirements relative to the normal and the transient operations of the whole system to be satisfactorily achieved.

All the above confirms that there is room for improving the exciter performance and efficiency. Therefore, the second part of this work aims at providing an alternative way to compensate for this system inefficiency. This is based on the identification and implementation of an optimal design of the excitation system of the GenSet.

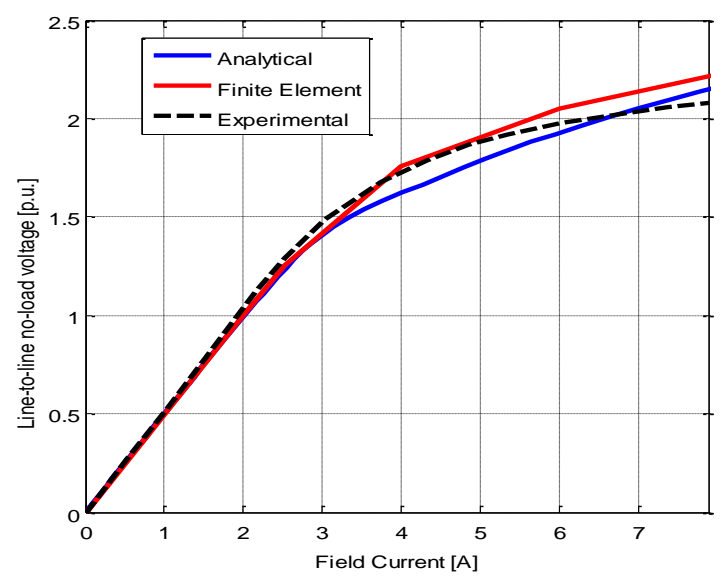

Fig. 9. No-Load Characteristics - Comparison.

\section{The Proposed Design Optimization ToOl}

The analytical evaluation of the machine inductance described in Section III allows for a very accurate prediction of the performance of the exciter studied in this paper, as shown in Section IV. In particular, this first part of the paper has shown how the proposed model is excellently suited when the rectifier commutation processes have to be taken into account. It is thus possible to achieve an excellent prediction of the commutation angle as well as of the voltage drop ensuing from the rectifier behavior.

An important aspect, related to the models described above, is their correct implementation into a preliminary sizing procedure of exciters for SGs. This will allow the machine designer to minimize the issues mentioned above and avoid at a design stage any malfunctioning due to the diode commutations in the rotating rectifiers of such excitation systems. For these reasons, the second part of the paper will focus on the implementation and the validation of a 
preliminary sizing procedure that is also used for optimization purposes in a more advanced GA-based design tool. All these aspects will be discussed in the next sections.

\section{A. Introduction}

A typical approach widely used in the design of electrical machines consists in a preliminary, analytical sizing which is then fine-tuned by FE analysis, to meet the desired requirements in line with the specific application. Sizing equations have been extensively studied and applied for the design of electrical machines [16-21] in a wide range of applications [22-24]. However, with recent advancements in computational resources, numerical techniques such as FE [25-29] are often preferred to analytical methods due to the complexity and non-linearity of the studied problems. Recently, more innovative optimization techniques, employing GAs have been shown capable to further improve electrical machines' performance [30, 31]. These techniques, which include deterministic and stochastic methods [32] are finding an ever increasing role in machine design, as the optimization synthesis of electrical machines is often a multi-objective problem [33]. A review of recent developments in electrical machine design optimization methods is presented in [34].

While the above has been widely described in the recent literature, to the authors' knowledge no such work has been applied to the exciters of SGs, in particular when the impact of the diode commutations is not negligible. Hence, a preliminary sizing procedure is first developed and the tools described and validated in the previous sections are thus used to estimate the inductance, the voltage drop and the new operating point.

\section{B. Preliminary Sizing Procedure}

The first, essential requirement in the design procedure of the exciters is the need to operate at the same rotational speed as the main SG. A degree of freedom is permitted in the choice of the number of phases for the exciter's armature winding. However, a three-phase winding is by far the most common type, in conjunction with a three-phase, six-pulse diode rectifier which produces a low ripple DC output. This common arrangement, i.e. a three-phase exciter armature winding feeding into a three-phase rectifier, is shown in Fig. 2.

The operational requirements of the exciter are usually defined by the operation of the main generator, including its transient performance. These include:

1) The prime mover rotational speed $n$;

2) The field voltage $V_{m g}$ and the field current $I_{m g}$ required by the generator at steady state operation

3) The field voltage $V_{m g(O L)}$ (also known as ceiling voltage) and the field current $I_{m g(O L)}$ (also known as ceiling current) required by the generator on overload/transient operation.

This usually results in an 'over-sizing' of the machine in order to meet the required transient performance. In other words, when the main SG operates at full-load condition, the exciter is expected to work in linear conditions. At this design stage, classical diode bridge theory [4] is usually used to convert between DC and AC quantities, where the commutations aspects are often neglected. Hence, the line-to-line voltage and the phase current of the exciter can be derived. At this stage, it is well known that the currents supplied by the exciter are non- sinusoidal, as the load of this machine is represented by the diode rectifier which is a purely non-linear load. These aspects can be taken into account in the sizing procedure of the exciter.

The choice of the number of poles is also an important step of the design process. In general, a basic rule can be considered: the stator and rotor yokes' thickness decreases by increasing the number of poles $2 p$.

Initial values of the electric loading and the airgap magnetic loading are necessary to estimate the well-known $D_{a g}{ }^{2} L[16$, 17], where $D_{a g}$ is the airgap diameter and $L$ the axial length of the machine. In applications where the frame which hosts the exciter limits the machine length, this can be used as an input for the design. Alternatively, when a family of exciters has to be designed using the same stator and rotor laminations, then an appropriate ratio $L / D_{a g}$ can be used as an input of the design process.

The rotor and the armature winding design procedures are not reported in detail in this paper, as they are similar to the approaches shown in literature for the most common electrical machines [12]. However, for the exciters of SGs, it is worth mentioning that very low values of the maximum flux densities allowed in the various parts of the machine can be selected at this stage in order to consider the "oversizing" aspects mentioned above. The outputs of this sizing stage are listed below:

1) The number of rotor slots;

2) The number of turns per phase;

3) The conductor's cross-sectional area;

4) The rotor tooth width;

5) The rotor slot width;

6) The rotor slot depth.

The airgap thickness has to comply with the general and 'always valid' considerations concerning the minimization of the magnetic voltage drop in the airgap and the mechanical constraints due to the movement of the rotating parts of the machine. However, as well as for the number of poles, in the next sections it will be shown how the airgap length can play an important role in the design synthesis of the particular exciter considered in this work, as it can significantly affect the voltage drop due to the diodes' commutations.

As well as for the rotor design, the calculations related to the stator (i.e. the pole width, the pole arc width and the yoke thickness) are not shown as they comply with the classical theory and sizing equations of electrical machines.

After the steps described above, all the dimensions of the exciter needed for determining the magnetic voltage drops along the parts of the machine are known. It is then possible to evaluate the total magneto-motive force $F_{T O T}$ that the exciter field winding has to provide to compensate for the magnetic drops.

Also the AVR parameters play an important role in the design of this machine. After having chosen the AVR in accordance with the generator ratings and on the base of economic reasons, the exciter field winding can be designed in accordance with its parameters, which are

1) The AVR maximum output voltage;

2) The continuous and intermittent DC current levels;

3) The reference value for the exciter field resistance $R_{f w_{-} e x c}$. 
Based on the above considerations, a preliminary sizing procedure is developed and this is illustrated in Fig. 10.

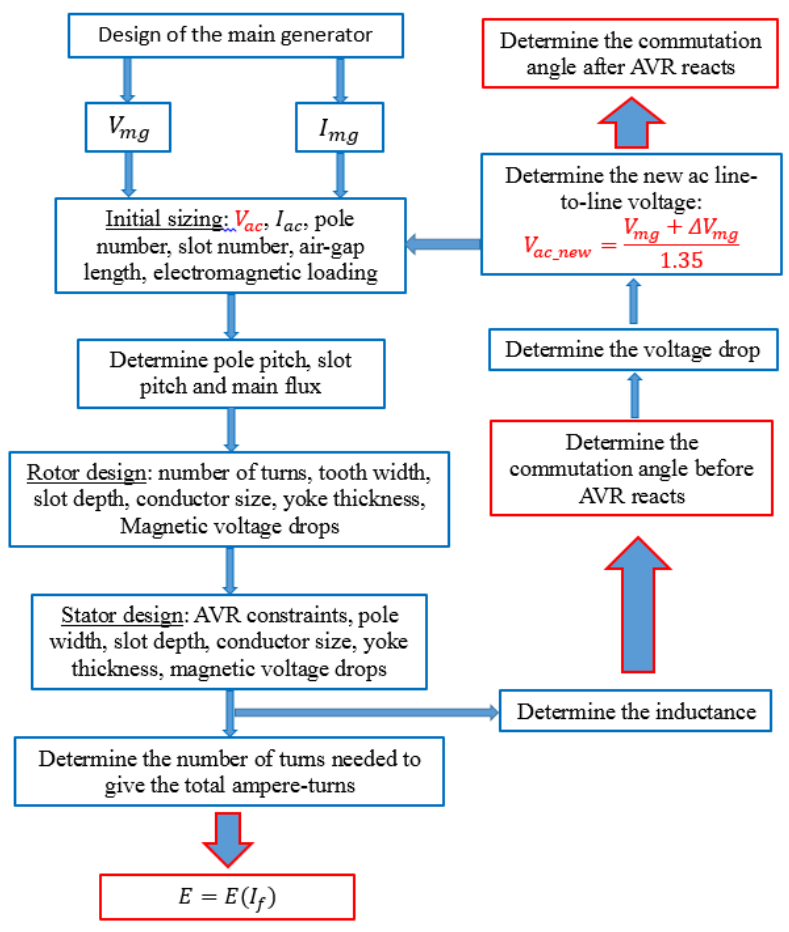

Fig. 10: Top level flow chart of the exciter sizing procedure.

C. No-load curve, inductance, voltage drop and efficiency determination

Having determined all the dimensions of the stator and rotor parts and the design of the armature and the field windings, the next step consists in estimating the no-load characteristic of the exciter. By implementing the magnetization curve of the ferromagnetic materials used for the rotor and stator stacks, it is a simple task to extrapolate the no-load rotor output voltage as a function of the stator field current.

Also the inductance can be determined once the machine design is completed. Both the magnetizing and the leakage inductances can be evaluated by using the methods described in Section III.

Proven the importance of the exciter phase inductance in the commutation processes described in Section II, the voltage drop and the real operating point of the machine can be evaluated as in (8) and (11), respectively.

The final step of this design stage consists in determining the machine losses, aiming at evaluating the overall efficiency of the considered $5.35 \mathrm{kVA}$ exciter. Although the loss estimation is a challenging task, especially when analytical expressions have to be employed, the following terms can be estimated and used for sensitivity and optimization purposes:

1) Resistive losses, from the winding geometry and the estimated currents in the stator and rotor phases;

2) Iron losses, from the geometry of the magnetic parts, the operating flux densities and the specific loss of the ferromagnetic steel;

3) Mechanical losses, by using the well-known experimental Schuisky's equation [34].
A relatively accurate approximation of the losses and efficiency of the machine can then be achieved.

\section{FE and Experimental Validation of the Sizing Tool}

In the previous sections, top level considerations and indetail equations related to the design of an exciter for SGs have been described. In particular, it has been shown that the electromagnetic design of an exciter strongly depends on the operational requirements of the main $\mathrm{SG}$, including its transient performance. In fact, in order to accomplish the overload performance of the main SG, the exciter is designed according to the logic of selecting very low values of the flux densities in the various parts of the machine and a low current density into the windings. In this way, it is ensured that the exciter will comply with the ceiling performance, as also proven by the fact that, at full-load, the machine fully operates in linear condition (i.e. the ferromagnetic materials are not saturated). Taking into account the above aspects, the classical sizing equations of electrical machines can be then applied also to the design of the exciter. Finally, the voltage drop due to the commutations and the new voltage value at which the exciter has to work to compensate for it can be determined. As the voltage drop was an identified issue at the particular fullload operation of the main generator, the exciter performance during transients is not evaluated as it would be out of the scope of the paper.

In order to validate the implemented procedure, FE and available experimental results of a baseline machine, i.e. the exciter being analysed in this work, are used. Transient with motion simulations have been performed to evaluate the FE open-circuit characteristic of the exciter, while the set-up discussed in Section IV.B is used for the experimental evaluation. In Fig. 9 this comparative exercise can be observed, showing an excellent similarity amongst the three curves.

Having validated the sizing tool described above, it can be used for optimizations purposes. From the results shown in Section III and IV, it can be observed that there is still room for improving the design procedure of this relatively small machine. The following sections focus on a detailed sensitivity analysis aimed at limiting the exciter design space and on the development of an accurate GA-based design tool.

\section{E. Sensitivity analysis}

Considering the need and the importance of the exciter's phase inductance in determining the voltage drop described by (8), it is then clear that all the parameters involved in (10) can be utilized to improve the overall performance and efficiency of the machine. Thus, a sensitivity analysis on the main machine parameters that have an effect on the voltage drop is performed. Although the results of this exercise can vary depending on the power range, the geometrical and magnetic features, the control scheme etc. of the excitation system under analysis, for the particular case study considered in this work they can provide very useful information for a first exploration of the design space. For the second stage, a quicker resolution of the optimization problem can then be achieved.

In Fig. 11 and 12, the results of this analysis can be observed. The number of pole pairs and the axial length of the 
machine are the design parameters that mostly influence the voltage drop as well as the efficiency. These parameters can achieve a lower voltage, however at the cost of a lower efficiency. The air-gap thickness also strongly affects the voltage drop, but without influencing the efficiency significantly. The aspect ratio, (axial length/rotor inner diameter) evaluation shows an interesting trend of the voltage drop, however without significantly affecting the machine efficiency. Also the split ratio (inner stator diameter/outer stator diameter), although shown in a small variation range due to geometrical constraints, seems to be an interesting parameter for the voltage drop minimization.

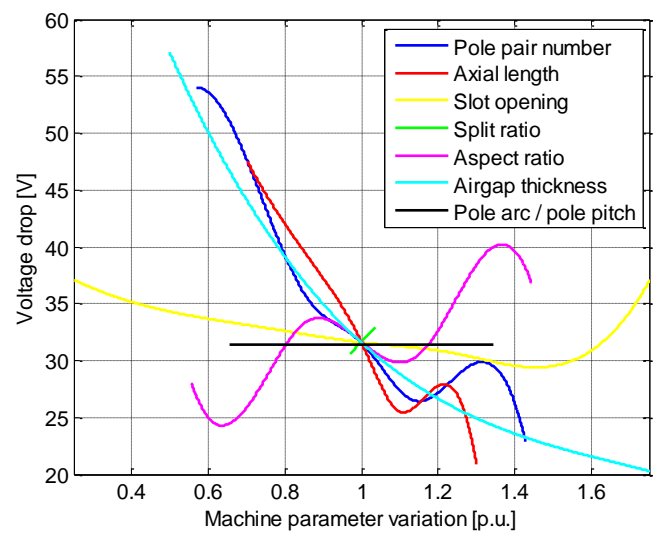

Fig. 11. Sensitivity analysis - voltage drop variation.

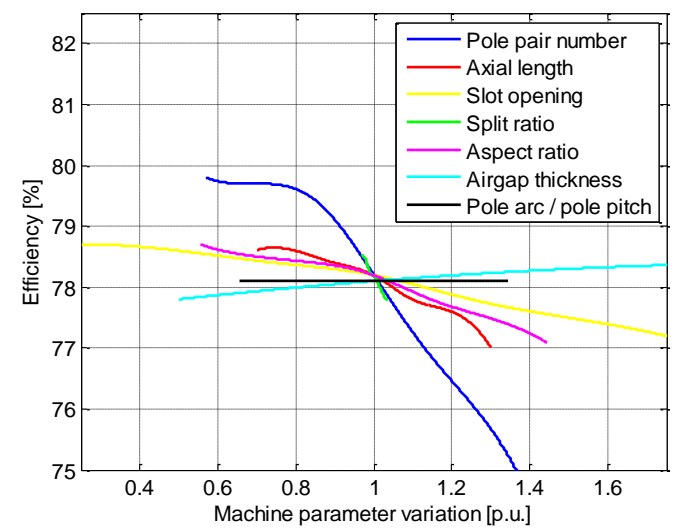

Fig. 12. Sensitivity analysis - efficiency variation.

According to the results shown above in Fig. 11 and Fig. 12, the selected input parameters and the relevant constraints used for developing the optimization tool are the followings:

1) the number of pole pair $p$, constrained from $1 p . u$. to $1.43 p . u$., as a lower number would negatively affect the voltage drop, whereas a higher number would lead to an unacceptable efficiency drop;

2) the axial length $l$, constrained from $0.8 p . u$. to $1.1 p . u$., as one of the objective is also that of reducing this machine design parameter, although an increased $l$ would potentially lead to a significant voltage drop reduction;

3) The airgap thickness $\delta$, constrained from $0.8 p$.u. to $2 p . u$, taking into account that a smaller $\delta$ would increase the voltage drop, while a thicker airgap would lead to a higher $\mathrm{mmf}$ drop, to be compensated by an increased number of field winding turns;

4) The split ratio $S R$, constrained from 0.95 p.u. to 1.05 p.u., taking into consideration the structural, geometrical limitations of the exciter on one hand and, on the other hand, a maximum allowed machine outer diameter. The latter in fact is limited by the size of the case which contains the whole GenSet

\section{F. The Analytical-GA-based Optimization Tool}

Aim of this section is to describe the purely analytical optimization tool aimed at finding all the possible design solutions which minimize the voltage drop, while keeping the efficiency above acceptable limits. The output variables chosen as optimization objectives are therefore the voltage drop and the exciter field winding resistance $R_{f w_{-} e x c}$, which is an indicator of the efficiency as it affects power losses. However, priority is given to the voltage drop minimization objective. In particular, this has to be lower than the value estimated for the baseline machine $\left(\Delta V_{m g}=32.2 V\right)$. On the other hand, it is sufficient that $R_{f w_{-} e x c}$ is kept between $18 \Omega$ and $21 \Omega$, in order to comply with the constraints imposed by the AVR (see Section V.B) while keeping the efficiency above acceptable limits.

The optimization process is initialized by preliminary exploring the design space through the use of design of experiments (DoE) techniques [36]. In this first stage of the procedure, an initial population of potential designs is assigned to the optimization algorithm. A preliminary optimization is then performed by using a Multi-Objective Genetic-Algorithm (MOGA). This model uses a smart multisearch elitism that is able to preserve some excellent solutions without bringing premature convergence to local-optimal frontiers [37]. In the end, a refinement is performed by using the best solutions of the previous iteration.

The optimization results for the $5.35 \mathrm{kVA}$ exciter considered in this paper are shown in Fig. 13. It is shown how several designs can achieve a voltage drop (on the $\mathrm{x}$-axis) that is lower than $30 \mathrm{~V}$ and a field resistance (on the y-axis) that can be maintained under the reasonable value of $21 \Omega$, as highlighted in the target area. Amongst the optimal designs shown in the graph, only one solution is chosen for further analysis. In Table IV, a comparison between the dimensions of this optimal machine and those of the existing one is shown. Also, in the last column of the same table, it can be observed that an increased efficiency is achieved with the optimized solution.

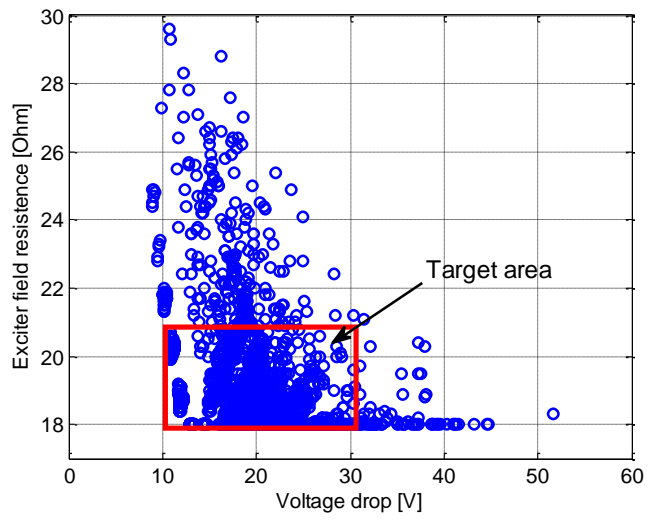

Fig. 13. Optimization results - Field winding resistance vs. voltage drop. 
TABLE IV

COMPARISON BETWEEN EXISTING AND OPTIMIZED DESIGNS

\begin{tabular}{|c|c|c|c|c|c|c|}
\hline------ & $\boldsymbol{l}$ & $\boldsymbol{p}$ & $\boldsymbol{\delta}$ & $\mathbf{S R}$ & $\boldsymbol{\Delta V}$ & $\boldsymbol{\varepsilon}$ \\
\hline $\begin{array}{c}\text { Existing } \\
\text { Design }\end{array}$ & $50 \mathrm{~mm}$ & 7 & $1 \mathrm{~mm}$ & 0.753 & $32.2 \mathrm{~V}$ & $78.2 \%$ \\
\hline $\begin{array}{c}\text { Proposed } \\
\text { Design }\end{array}$ & $48 \mathrm{~mm}$ & 7 & $1.4 \mathrm{~mm}$ & 0.733 & $23.0 \mathrm{~V}$ & $78.9 \%$ \\
\hline
\end{tabular}

Table IV also provides the following optimization features with respect to the new, proposed design:

1) the axial length is smaller than that of the existing machine, then allowing for a more compact design;

2) the number of poles is the same as the actual machine;

3) the airgap is bigger than that of the baseline machine, then resulting in an increased number of field winding turns. However, the field resistance is 'controlled' by the implemented GA, allowing for the efficiency to be even improved;

4) A voltage drop reduction of about $28 \%$ can be achieved.

The best performing solution identified above is then analyzed via a 2-D FE transient with motion simulation. The stator and rotor circuits are coupled to the 2-D FE model, as shown in Fig. 2. A comparison between the registered currents on the DC bus, i.e. the field winding of the main SG, is shown in Fig. 14. By using the same exciter field winding current for both the machines, it can be observed how the improved design achieves an augmentation of the current available at the main generator rotor terminals, potentially allowing for the exciter to work with a lower field winding current, which in turn results in improvements of the overall efficiency.

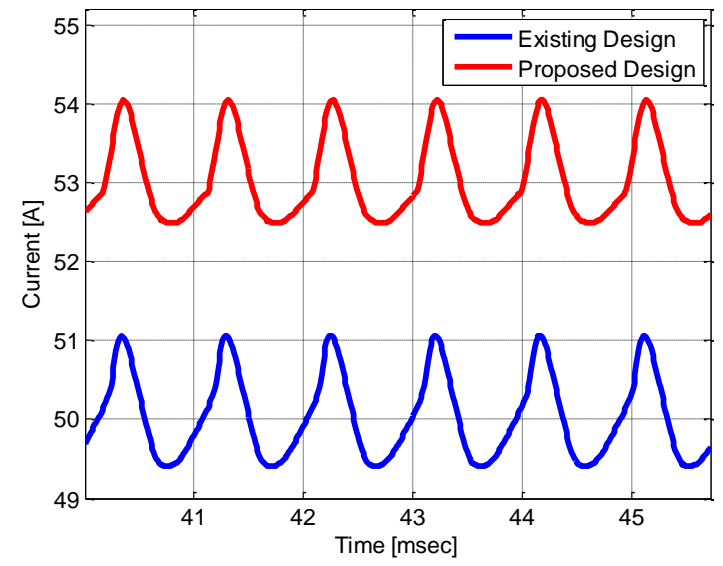

Fig. 14. Main generator rotor currents - Comparison.

\section{CONCLUSIONS}

This paper deals with the analysis and prediction of the voltage drop produced by the diode commutation processes in the 'classical' rotating diode bridge of SGs. A fully analytical and genetic-algorithm-based design tool aimed at minimizing the machine inductance and the ensuing voltage drop is proposed. As vessel to test, validate and expand upon the study, the work presented here was focused on a particular $5.35 \mathrm{kVA}$ brushless excitation system of a $400 \mathrm{kVA}$ SG, with special attention given to the rated, full-operation of the whole Genset.

In the first part of this work, aimed at evaluating the machine phase inductance, an equivalent-circuit-based approach was proposed and validated against FE and experimental results, with excellent similarity being achieved. The maximum error found at this stage was $8.2 \%$. The validated model was then included and implemented in a preliminary sizing procedure, which was further validated against the experimental data available for the baseline machine.

Having validated these tools and considering that a voltage drop of about $30 \%$ was found at the generator's rotor terminals, the second part of the paper deals with the description of an analytical, GA-based design tool, aimed at offering more efficient design methodologies to the GenSets' designers, especially for the aspects highlighted in this paper. In fact, the optimization results show that improved designs of the exciter can be obtained, which result in excellent achievements in terms of voltage drop reduction. The best design solution achieves a voltage drop reduction of $28 \%$ and an increased output of $5.64 \%$ in terms of available current at the main generator rotor terminals, which in turn results in an improved efficiency.

\section{REFERENCES}

[1] Dillman, T. L., Keay, F. W., Raczkowsi, C., Skooglund, J. W., and South, W. H., "Brushless Excitation," IEEE Spectrum, Mar. 1972, pp. $58-66$.

[2] "IEEE Standard Definitions for Excitation Systems for Synchronous Machines", IEEE Std. 421.1, 1996 (revised 1996).

[3] "IEEE Guide for the Preparation of Excitation System Specifications", IEEE Std. 421.4, 2014.

[4] B. Wu, "Multipulse Diode Rectifiers", in High-Power Converters and AC Drives, USA: Wiley-IEEE Press, 2006, Ch. 3, pp. 35-64.

[5] Z. Ren, K. Yu, Q. Xin, and Y. Pan, "Performance of Homopolar Inductor Alternator With Diode-Bridge Rectifier and Capacitive Load," IEEE Trans. Ind. Electron., vol. 60, no. 11, pp. 4891-4902, Nov.2013.

[6] D. C. Aliprantis, S. D. Sudhoff, and B. T. Kuhn, "A brushless exciter model incorporating multiple rectifier modes and Preisach's hysteresis theory," IEEE Trans. Energy Convers., vol. 21, no. 1, pp. 136-147, Mar. 2006.

[7] W. J. Bonwick, "Characteristics of a Diode-Bridge-Loaded Synchronous Generator Without Damper Windings", Proc. IEE, Vol. 122, No.6, June 1975, pp 637-641.

[8] M. A. Abdel-Halim and C. D. Manning, "Modeling a laminated brushless exciter-alternator unit in all modes of operation," Proc. Inst. Elect. Eng. B, vol. 138, no. 2, pp. 87-94, Mar. 1991.

[9] S. Jordan, C. Manolopoulos, J. M. Apsley, "Winding configurations for five-phase synchronous generators with diode rectifiers," IEEE Trans. Ind. Electron., vol. 63, no. 1, pp. 517-525, Jan. 2016.

[10] P. Bolognesi, "A Mid-Complexity Analysis of Long-Drum-Type Electric Machines Suitable for Circuital Modelling", in Proc. ICEM 2008 Conf., paper n. 99.

[11] Nuzzo S., Degano M., Galea M., Gerada C., Gerada D., Brown N. L., "Improved damper cage design for salient-pole synchronous generators", IEEE Trans. Ind. Electron., 2016.

[12] Pyrhonen, J., Tapani, J., and Hrabovcovà, V. (2008). Design of Rotating Electrical Machines. Chicester, UK: John Wiley \& Sons, Ltd.

[13] Nuzzo S., Galea M., Gerada C., Brown N. L., "Prediction of the voltage drop due to the diode commutation process in the excitation system of salient-pole synchronous generators", Proc. in the $19^{\text {th }}$ International of Electrical Machines and Systems, (ICEMS 2016), 2016. 
[14] Nuzzo S., Galea M., Gerada C., Brown N. L., "An analytical and genetic-algorithm-based design tool for brushless excitation sustems of low-medium rated synchronous generators", Proc. in the $19^{\text {th }}$ International of Electrical Machines and Systems, (ICEMS 2016), 2016.

[15] Bianchi, N., Electrical Machine Analysis Using Finite Elements. 2005: Crc.

[16] V. B. Honsinger, "Sizing equations for electrical machinery," IEEE Trans. Energy Conversion, vol. EC-2, pp. 116-121, Mar. 1987.

[17] A. Boglietti, A. Cavagnino, M. Lazzari, S. Vaschetto, "Preliminary induction motor electromagnetic sizing based on a geometrical approach", IET Electric Power Application, vol 6, no. 9, pp. 583-592, Feb. 2012.

[18] P. D. Pfister and Y. Perriard, "Very-high-speed slotless permanentmagnet motors: Analytical modeling, optimization, design, and torque measurement methods," IEEE Trans. Ind. Electron., vol. 57, no. 1, pp. 296-303, Jan. 2010.

[19] L. Y. Shao, W. Hua, N. Y. Dai, M. H. Tong, and M. Cheng, "Mathematical modeling of a twelve-phase flux-switching permanent magnet machine for wind power generation," IEEE Trans. Ind. Electron., vol. 63, no. 1, pp. 504-516, Jan. 2015.

[20] W. Hua, H. Zhang, M. Cheng, J. Meng, and C. Hou, "An outer-rotor flux-switching permanent-magnet-machine with wedge-shaped magnets for in-wheel light traction," IEEE Trans. Ind. Electron., vol. 64, no. 1, pp. 69-79, Jan. 2017.

[21] T. Raminosoa, C. Gerada, M. Galea, "Design Considerations for a FaultTolerant Flux-Switching Permanent-Magnet Machine," IEEE Trans. Ind. Electron., vol. 58, no. 7, pp. 28182825, July 2011.

[22] P. E. Kakosimos, A. G. Sarigiannidis, M. E. Beniakar, A. G. Kladas, and C. Gerada, "Induction motors versus permanent-magnet actuators for aerospace applications," IEEE Trans. Ind. Electron., vol. 61, no. 8, pp. 4315-4325, Aug. 2014.

[23] A. Tenconi, S. Vaschetto, and A. Vigliani "Electrical machines for highspeed applications: Design considerations and trade-offs," IEEE Trans. Ind. Electron., vol. 61, no. 6, pp. 3022-3029, Jun. 2014.

[24] A. Griffo, D. Drury, T. Sawata, P.H. Mellor, "Sensorless starting of a wound-field synchronous starte-generator for aerospace applications," IEEE Trans. Ind. Electron., vol. 59, no. 9, pp. 3579-3587, Sep. 2012.

[25] A. Tessarolo, C. Bassi, D. Giulivo, "Time-stepping finite-element analysis of a 14-MVA salient-pole shipboard alternator for different damper winding design solution," IEEE Trans. Ind. Electron., Vol. 59, No. 6, pp. 2524-2535, June 2012.

[26] K. S. Jiji, N. H. Jayadas, C. A. Babu, "FEM-based Virtual Prototypingand Design of Third Harmonic Excitation System for LowVoltage Salient-Pole Synchronous Generators", IEEE Trans. Ind. Electron., vol. 50, no. 3, May/June 2014.

[27] Nuzzo S., Galea M., Gerada C., Gerada D., Mebarki A., Brown N. L., "Damper Cage Loss Reduction and No-Load Voltage THD Improvements in Salient-Pole Synchronous Generators", Proc. in Power Electronics, Machines and Drives (PEMD 2016), $8^{\text {th }}$ IET International Conference on., 2016.

[28] B. Marcusson, U. Lundin, "Finite-element calculation of 3-D transient electromagnetic field in end regionh and eddy-current loss decrease in stator end clamping plate of large hydrogenerator," IEEE Trans. Ind. Electron., vol. 62, no. 12, pp. 7331-7338, Dec. 2015.

[29] S. Nuzzo, M. Galea, C. Gerada, N. Brown, "A fast method for modelling skew and its effects in salient-pole synchronous generators", IEEE Trans. Ind. Electron., vol. PP, no. 99, pp. 1-1, 2017.

[30] A. Boglietti, A. Cavagnino, M. Lazzari, "Computational Algorithms for Induction Motor Equivalent Circuit Parameter Determination Part I: Resistances and Leakage Reactances", IEEE Trans. Ind. Electron., Vol. 58, No. 9, pp. 3723-3733, Sep. 2011.

[31] H. M. Hasanien, "Particle swarm design optimization of transverse flux linear motor for weight reduction and improvement of thrust force," IEEE Trans. Ind. Electron., vol. 58, no. 9, pp. 4048-4056, Sep. 2011.

[32] J.Fontchastagner, F. Messine, andY. Lefèvre, "Design of electrical rotating machines by associating deterministic global optimization algorithm with combinatorial analytical and numerical models," IEEE Trans. Magn., vol. 43, no. 8, pp. 3411-3419, Aug. 2007.

[33] P. Ponomarev, I.Petrov, N. Bianchi, and J. Pyrhonen, "Selection of Geometric Design Variables for Fine Numerical Optimizations of Electrical Machines," IEEE Trans. Magn., vol. 51, no. 12, Dec. 2015.
[34] D. Yao and D. M. Ionel, "A review of recent developments in electrical machine design optimization methods with a permanent-magnet synchronous motor benchmark study," IEEE Trans. Ind. Appl., vol. 49, no. 3, pp. 1268-1275, Sep. 2013.

[35] Schuisky W., Design of Electrical Machines (BerechnungelektrischerMaschinen), Springer Verlag, Vienna, 1960.

[36] Ma Cong, Qu Liyan "Multiobjective Optimization of Switched Reluctance Motors Based on Design of Experiments and Particle Swarm Optimization," IEEE Trans. Energy Convers., vol. 30, No. 3, Sep. 2015.

[37] Poles S., Technical Report 2003-006, "MOGA-II An improved MultiObjective Genetic Algorithm.

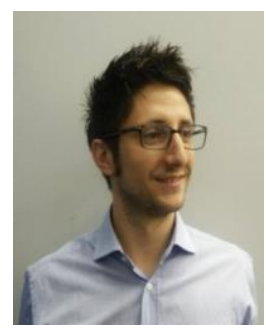

S. Nuzzo (S'17) received the B.Sc. and M.Sc. degrees in electrical engineering from the University of Pisa, Pisa, Italy, in 2011 and 2014, respectively. He is currently working toward the Ph.D. degree at the Power Electronics, Machines and Control Group, The University of Nottingham, Nottingham, U.K.

He spent six months with The University of Nottingham as a Visiting Student in 2013, where he was involved in developing analytical and numerical models for the analysis of permanent magnet synchronous machines. His current research interests include the analysis and design of salient-pole SGs and brushless excitation systems.

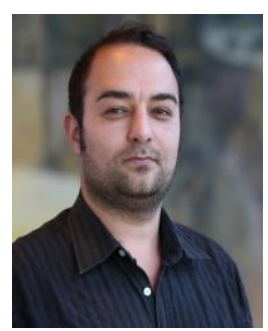

Michael Galea (M'13) received the Ph.D. degree in electrical machines design from The University of Nottingham, Nottingham, U.K., in 2013.

He was a Research Fellow with The University of Nottingham, where he is currently a Lecturer in electrical machines and drives within the Power Electronics, Machines and Control

Group. He is the Deputy Director of the Institute for Aerospace Technology, The University of Nottingham, where he is also a Lecturer in aerospace systems integration and where he manages a number of diverse projects related to the more/all electric aircraft and associated fields. His main research interests include design, analysis, and thermal management of electrical machines and drives and the more electric aircraft.

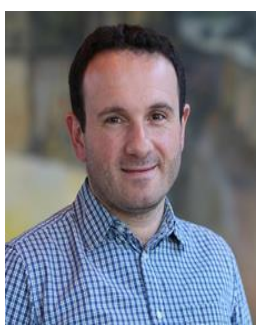

Chris Gerada (M'05-SM'12) received the Ph.D. degree in numerical modelling of electrical machines from The University of Nottingham, Nottingham, U.K., in 2005.

He was a Researcher with The University of Nottingham, working on high-performance electrical drives and on the design and modelling of electromagnetic actuators for aerospace applications. Since 2006, he has been the Project Manager of the GE Aviation Strategic Partnership. In 2008, he became a Lecturer in electrical machines, in 2011, as an Associate Professor, and in 2013, a Professor at The University of Nottingham. His main research interests 
include the design and modelling of high-performance electric drives and machines.

Prof. Gerada serves as an Associate Editor for the IEEE TRANSACTIONS ON INDUSTRY APPLICATIONS and is the Chair of the IEEE Industrial Electronics Society Electrical Machines Committee.

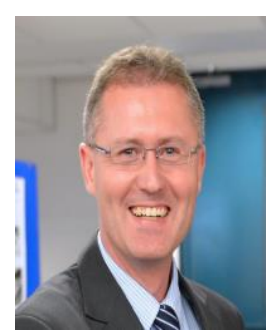

Neil Brown graduated at Nottingham Trent University, Nottingham, U.K., in 1991, and received the Ph.D. degree in electrical machines from Durham University, Durham, U.K., in 2003.

$\mathrm{He}$ is currently a Visiting Professor at The University of Nottingham, Nottingham, U.K. He joined Cummins in 1995, and is the Chief Engineer Stamford Products, Cummins Generator Technologies, Stamford, U.K. While at Cummins, he has held various roles, including Applications Engineer, Electromagnetic Design Engineer, Research Manager, Chief Engineer for Stamford Products, Chief Engineer Research and Technology, and Director, Advanced Electrical Machines, before returning to his role as Chief Engineer Stamford Products in 2016. Before his time at Cummins, he ran his own electrical business, was a College Lecturer, and worked for GEC on projects up to 100 MVA. He is the author of 80 publications, named inventor of 11 patents, and the co-inventor of the "Haydock Brown Machine.

Dr. Brown is a certified Six Sigma Green Belt and Sponsor, a Chartered Engineer, in the U.K. and a Fellow of the Institution of Engineering and Technology, U.K. 